PACS: $61.72 \mathrm{y}, 81.05, \mathrm{Dz} ; 81.10 . \mathrm{Bk}$

\title{
$C d_{1-\mathrm{x}} \mathrm{Zn}_{\mathrm{x}} \mathrm{Te}$ high-resistive single crystals growth from a vapor phase
}

\author{
P. Feychuk ${ }^{1}$, O. Kopyl ${ }^{2}$, I. Pavlovich ${ }^{2}$, L. Shcherbak ${ }^{1}$ \\ ${ }^{1}$ Chernivtsi National University, 2, Kotsyubinsky str., 58012 Chernivtsi, Ukraine \\ E-mail:feychuk@chnu.cv.ua \\ ${ }^{2}$ Institute of Thermoelectricity, P. O. Box 86, 58002 Chernivtsi, Ukraine
}

\begin{abstract}
A modified vapor phase growth method to obtain high-resistive $\mathrm{Cd}_{1-x} \mathrm{Zn}_{x} \mathrm{Te}$ single crystals $(0<x<0.13)$ is presented. The single crystals (about $25 \mathrm{~cm}^{-3}$ in size) with natural faceting were grown by vapor transport in silica ampoules with a special shape using a polycrystalline ingot as initial source material. It is shown that minimization of plastic deformation effect in preparation of the most structurally perfect crystals is possible by a way of heat removal from the crystallization front by radiation. The growth of high-resistive material required careful preparation of the initial charge with close to stoichiometric composition. The obtained crystals were successfully tested for creating the room temperature X-ray and gamma-ray detectors.
\end{abstract}

Keywords: $\mathrm{CdTe}, \mathrm{Cd}_{1-x} \mathrm{Zn}_{x} \mathrm{Te}$, vapor crystal growth, high resistivity, gamma-ray detectors.

Manuscript received 17.12.04; accepted for publication 18.05.05.

\section{Introduction}

Both CdTe and $\mathrm{Cd}_{1-\mathrm{x}} \mathrm{Zn}_{\mathrm{x}}$ Te single crystals are known as very good materials for room temperature gamma- and X-ray detectors [1, 2] and have many various applications in optoelectronics (IR-devices, photorefractive materials, solar cells, etc). For this purpose, the crystals with low density of linear and bulk structure defects (dislocations, grain boundaries, inclusions, and precipitates) are desirable in the most cases. $\mathrm{Cd}_{1-\mathrm{x}} \mathrm{Zn}_{\mathrm{x}}$ Te bulk crystals are grown from the melt usually. $\mathrm{Zn}$ presence causes the rises of the melt crystallization temperatures and makes the crystals growth from the liquid phase more complicated, especially at high $x$. Besides, for the application in the gamma-ray detectors, it is necessary to use high-resistive material with a high $\mu \tau$-product, which is reached usually by doping (In or $\mathrm{Cl}$ ) only. In this connection, comparatively low temperatures during vapor growth have attracted increasing interest of researches [3 -5].

Vapor growth methods can be divided by three main directions according to degree of a growing crystal interaction with container and vapor flows [3-10]:

- single crystal growth on a seed or a quartz container bottom with final completing of the container crosssection [5-7];

- free growth without contact with the container walls (free-contact growth on a quartz or single crystal pedestal) $[3,8]$;

- growth on broken [4] or previously formed ingot $[9,10]$.
Second method requires to use ampoules of rather complex construction in the solid solution crystals growth case. Composition and structure of the obtained crystals are inhomogeneous along the ingot due to a difference between temperatures of the starting charge and condensed material behind the crystal [11].

In [12], it was concluded that there are dislocations and small-angle grain boundaries generated at the interface in heterogeneous nucleation on the quartz container walls mostly due to mechanical stresses. The last are caused by mismatch between thermal expansion coefficients of the container and the crystal even at slight temperature variations $(\sim 0.1 \mathrm{~K})$. Estimations [12] show that about $10^{3} \mathrm{~cm}^{-2}$ dislocations can be generated during one variation cycle.

The aim of this paper is to eliminate advantages and disadvantages of the third method of the solid solution growth, namely, the modified method of Lo et al. [10] using polycrystalline compounds as the source material. The results obtained by researchers upon the possibility to grow the high-resistive $\mathrm{Cd}_{1-\mathrm{x}} \mathrm{Zn}_{\mathrm{x}} \mathrm{Te}(0<x<0.13)$ single crystals with natural faceting on polycrystalline charge and their conceivable applications are discussed.

\section{Experimental procedure}

Polycrystalline charges $\mathrm{Cd}_{0.96} \mathrm{Zn}_{0.04} \mathrm{Te}_{1 \pm \delta} \quad$ and $\mathrm{Cd}_{0.87} \mathrm{Zn}_{0.13} \mathrm{Te}_{1 \pm \delta}$ were synthesized (using $6 \mathrm{~N} \mathrm{Cd}, \mathrm{Zn}$ and $\mathrm{Te}$ ), melted and rapidly cooled in evacuated (up to $10^{-2} \mathrm{~Pa}$ ) uncoated silica ampoules with diameter of 35 to 

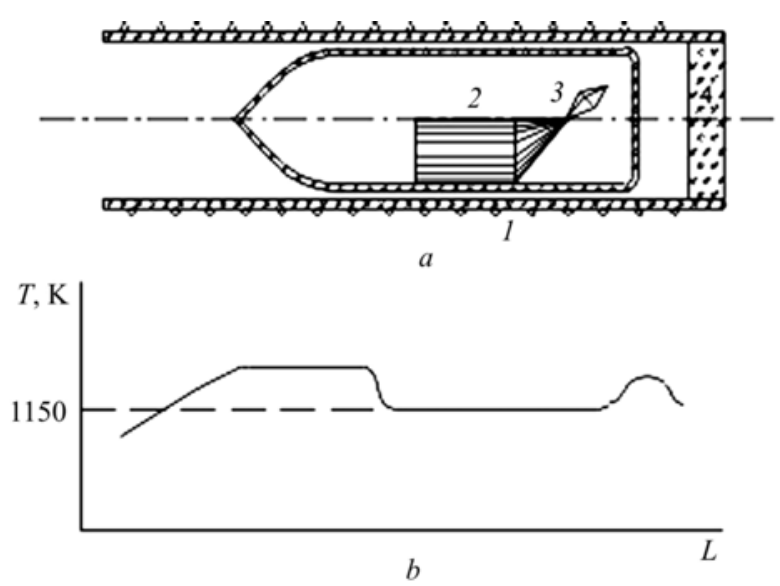

Fig. 1. Sketch of the growth ampoule and the temperature profile in the $\mathrm{Cd}_{1-\mathrm{x}} \mathrm{Zn}_{\mathrm{x}}$ Te crystal growth zone by the Lo et al. [10] method: 1 - furnace, 2 - charge, 3 - growing crystal.
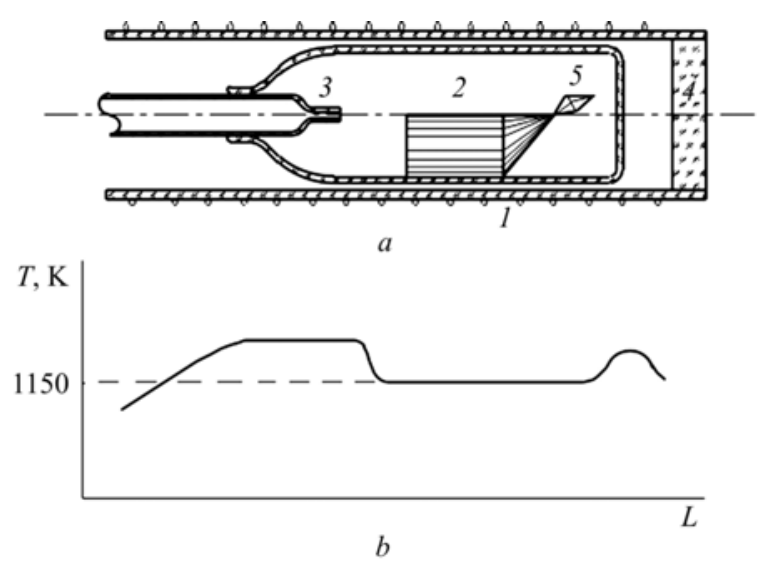

Fig. 2. A modified in the present work ampoule and temperature profile in the furnace for $\mathrm{Cd}_{1-\mathrm{x}} \mathrm{Zn}_{\mathrm{x}} \mathrm{Te}$ vapor growth: 1 - furnace, 2 - initial charge, 3 - capillary, 4 - silica window, 5 - growing crystal.

$40 \mathrm{~mm}$. The compact boule was placed in the growth ampoule which was evacuated with or without argon. The crystal growth experiments were performed in a two-zone furnace at $1053 \ldots 1223 \mathrm{~K}$. The temperature of the excess component condensation zone varied between 600 to $1000 \mathrm{~K}$. Computerized temperature control of the initial charge, crystal growth and excess component condensation zones was provided using $\mathrm{Pt} / \mathrm{PtRh}$ thermocouples with an accuracy $\pm 0.1 \mathrm{~K}$. The nucleation process control was carried out using a special optical equipment up to complete fill of the container bottom in the course of nucleation on the bottom or during whole mass transfer process in the growing on the charge case.

Two types of the growing equipment were used during the experiments. The growth ampoule and temperature profile in the process of CdZnTe crystal growth by the original method [10] are illustrated by Fig. 1. The growth ampoule modified in this work is schematically depicted in Fig. 2.

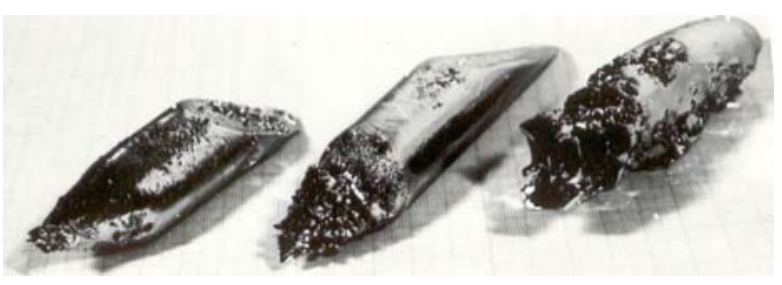

Fig. 3. Single crystals of $\mathrm{Cd}_{1-\mathrm{x}} \mathrm{Zn}_{\mathrm{x}}$ Te grown by the method [10]: $\mathrm{a}-x=0.13, \mathrm{~b}$ and $\mathrm{c}-0.04$. Initial charges were reached by the metal component $(\mathrm{a}, \mathrm{b})$ and $\mathrm{Te}(\mathrm{c})$.

The obtained crystal structure was controlled by metallographic and X-ray diffraction analysis methods. Besides, the selective chemical etching was carried out to determine the structure defect content and nature on the (111) and (110) surfaces of the prepared from the crystals wafers. The latter were polished in the Inoue etchant [13] followed by etching in $\mathrm{CrO}_{3}$ : $\mathrm{HF}: \mathrm{H}_{2} \mathrm{O}$ [14] or EAg-2 [13] solutions, accordingly. The structure morphology caused by the $\mathrm{Cd}$ or Te excess defects and the content of the latter were observed in an IR transmission microscope at $\lambda=1 \mu \mathrm{m}$. The inclusions nature was determined being based on elemental analysis data obtained using an electron beam microscope (JEOL).

The plates of $5 \times 5 \times 2 \mathrm{~mm}$ were cut from the ingot for detectors production and then mechanically polished in the fast polishing Inoue etchant [13] followed by the etching in $0.5 \%$ solution of $\mathrm{Br}_{2}$ in $\mathrm{CH}_{3} \mathrm{OH}$ to remove damaged layers.

The type of conduction, concentration and mobility of carriers in the obtained crystals were determined by Hall measurements. Ohmic contacts to the samples and diodes were produced by chemical deposition of $\mathrm{Au}$ from $\mathrm{HAuCl}_{4}$ solution and tested by current-voltage characteristics in the dark. Spectra of the planar detectors were taken using irradiation of $\mathrm{Ag}^{110}$ and $\mathrm{Cs}^{137}$ sources.

\section{Results and discussion}

Though the method of Lo et al. [10] have been rather successfully used in our experiments for vapor growing the $\mathrm{A}^{4} \mathrm{~B}^{6}$ crystals, perfect $\mathrm{Cd}_{0.96} \mathrm{Zn}_{0.04} \mathrm{Te}$ or $\mathrm{Cd}_{0.87} \mathrm{Zn}_{0.13} \mathrm{Te}$ crystals were not obtained, probably, because of a more narrow homogeneity region in $\mathrm{A}^{2} \mathrm{~B}^{6}$ compounds $[15,16]$ comparatively to $A^{4} B^{6}$ ones. The crystals which were grown from the enriched by a metallic component charges, had acicular surface structure (Fig. 3a, b) independently on $x$ value. When the starting charges had an excess of $\mathrm{Te}$, the obtained crystals were multigrain (Fig. 3c). Besides, the crystals have a high content level of the excess components. Thus, taking into account rather small CdTe [15] and CdZnTe [16] homogeneity region it must be concluded that it is necessary to fine control over the component deviation from stoichiometry during the growth process. 

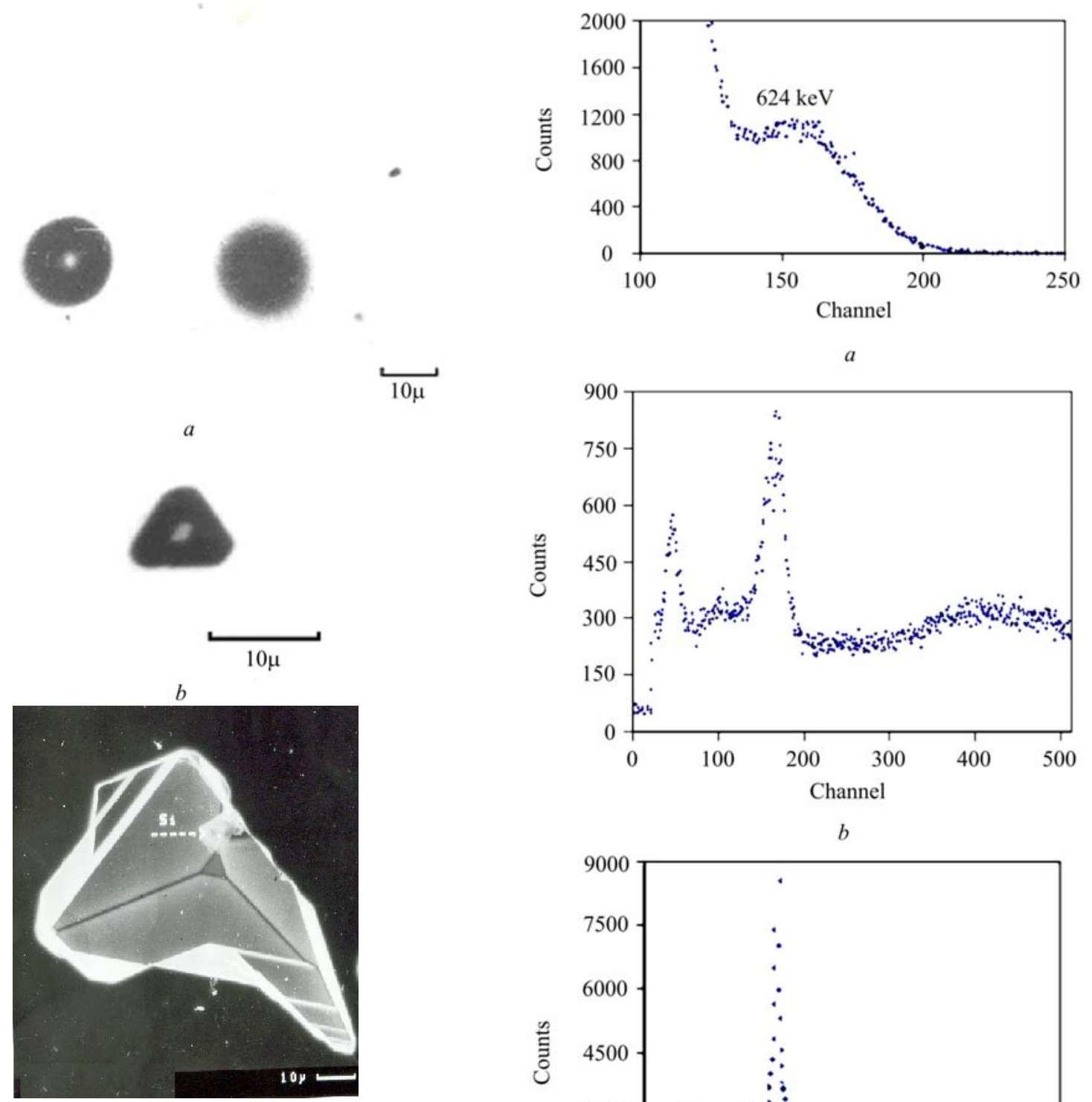

$b$
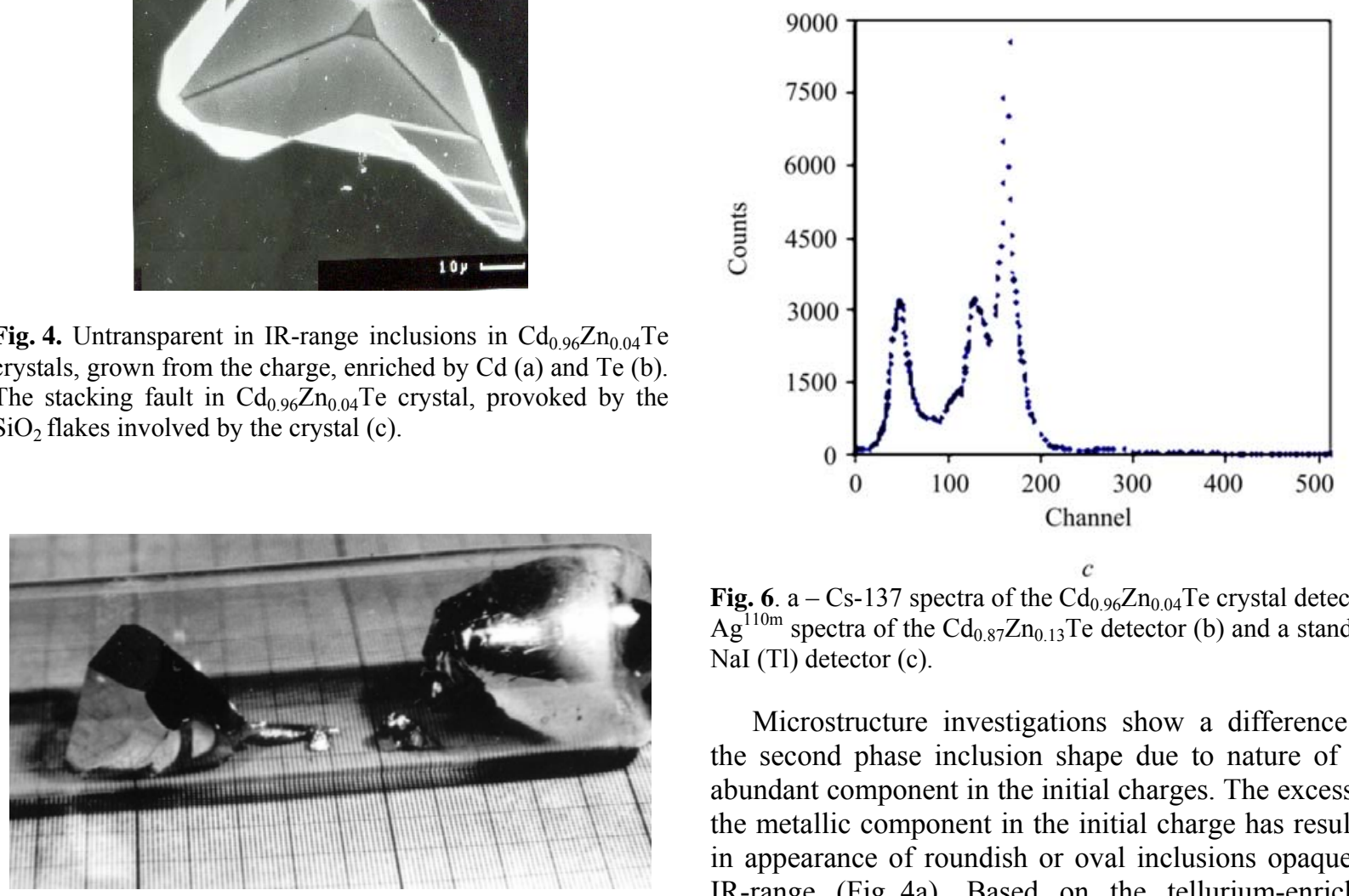

$c$

Fig. 4. Untransparent in IR-range inclusions in $\mathrm{Cd}_{0.96} \mathrm{Zn}_{0.04} \mathrm{Te}$ crystals, grown from the charge, enriched by $\mathrm{Cd}$ (a) and $\mathrm{Te}$ (b). The stacking fault in $\mathrm{Cd}_{0.96} \mathrm{Zn}_{0.04} \mathrm{Te}$ crystal, provoked by the $\mathrm{SiO}_{2}$ flakes involved by the crystal (c).

Fig. 5. a - An earlier stage of the $\mathrm{Cd}_{0.96} \mathrm{Zn}_{0.04} \mathrm{Te}$ crystal growing process by the modified method $[10] ; \mathrm{b}-$ the ampoule with the single crystal (left) and the residual initial charge (right).

Fig. 6. a - Cs-137 spectra of the $\mathrm{Cd}_{0.96} \mathrm{Zn}_{0.04} \mathrm{Te}$ crystal detector; $\mathrm{Ag}^{110 \mathrm{~m}}$ spectra of the $\mathrm{Cd}_{0.87} \mathrm{Zn}_{0.13}$ Te detector (b) and a standard $\mathrm{NaI}(\mathrm{Tl})$ detector $(\mathrm{c})$.

Microstructure investigations show a difference of the second phase inclusion shape due to nature of the abundant component in the initial charges. The excess of the metallic component in the initial charge has resulted in appearance of roundish or oval inclusions opaque in IR-range (Fig. 4a). Based on the tellurium-enriched initial charge, the grown crystals contain 3- or 6-edged precipitates that observed as dark figures in IR transmission microscope (Fig. 4b). The electron beam investigations gave a possibility to obtain $\mathrm{SiO}_{2}$ in- 
clusions as the excess component or vacancies condensation centers. Absorbed by the crystallization front the flakes of $\mathrm{SiO}_{2}$, generated from the ampoule walls, create stresses in the growing crystal due to a mismatch between the lattice parameters of the crystal and $\mathrm{SiO}_{2}$. Relaxation of strains in the crystal occurs due to migration of cadmium vacancies into the deformed range of the crystal and their cooperation followed by creation of tetrahedral stacking faults (Fig. 4c). Depending on the crystal cooling conditions, such defects can serve as sites for the excess component precipitations (Fig. 4b).

On the basis of the obtained data, it was concluded that a crystallization front convex shape had a most determinant influence on the crystal quality. Minimization of a plastic deformation effect that caused sub-grains and small-angle grain boundaries occurrence can be provided by heat removal from the crystallization front by radiation, not by the crystal thermal conductivity. For this purpose, the proposed in this paper modified ampoule construction had a beneficial effect. As a result, we have obtained the single crystals of about $25 \mathrm{~cm}^{-3}$ dimensions, constrained by natural faces corresponding to the (110), (100), and (111) planes (Fig. 4). Measuring the rocking curves half-height width for reflection planes $\left(\mathrm{Cu} K_{\alpha} \mathrm{X}\right.$-radiation) with the Miller indices (111), (220), (311), (422), and (331) gave 25.0", 17.5", 13.6", 20.8", and 13.6" values, respectively. X-ray patterns obtained with $\mathrm{Cu} K_{\alpha}$ radiation do not reveal any bulk defects or mechanical strains.

According to the microstructural study data, the dislocation density can be minimized up to $\sim 10^{3} \mathrm{~cm}^{-2}$. As a rule, room temperature resistivity of such crystals increases symbaticly with $\mathrm{Zn}$ content increase. Both $n$ and $p$ types of materials can be obtained by the deviation from stoichiometry changing from $n=3 \cdot 10^{14} \mathrm{~cm}^{-3}$ up to $p=1.7 \cdot 10^{15} \mathrm{~cm}^{-3}$, with carrier mobilities of 300 to $900 \mathrm{~cm}^{2} / \mathrm{V} \cdot \mathrm{s}$ and 50 to $70 \mathrm{~cm}^{2} / \mathrm{V} \cdot \mathrm{s}$ accordingly at $300 \mathrm{~K}$.

The grown crystal shape and size were defined both by the temperature gradient between growing and condensation zone and the deviation from the stoichiometry (vapor supersaturation). The single crystals growing rate reached as high as $2 \mathrm{~cm}^{3} /$ day. Separate phases of the growth process are demonstrated in Fig. 5. It must be noted that thought (111) plane preferential growth was obtained in earlier stages, later (100) plane becomes dominating. The best single crystals were characterized by a low density of dislocations (about $10^{3} \mathrm{~cm}^{-2}$ in $\mathrm{Cd}_{0.87} \mathrm{Zn}_{0.13} \mathrm{Te}$ ), minority quantity of the $\mathrm{SiO}_{2}+$ Te-based inclusions that are the usual defects grown by the Lo method [10], low X-ray rocking curve width $\left(13 \ldots 25^{\prime \prime}\right)$.

Using $\mathrm{Cd}_{0.96} \mathrm{Zn}_{0.04} \mathrm{Te}_{1 \pm \delta}+0.2 \mathrm{Ga}_{2} \mathrm{Te}_{3}$ alloy as an initial source, there were obtained rather perfect single crystals with $2 \cdot 10^{6} \mathrm{Ohm} \cdot \mathrm{cm}$ resistivity at $300 \mathrm{~K}$.

The obtained high-resistive solid solution crystals were successfully tested as room temperature X-ray and gamma-ray detectors. Fig. 6a shows a good resolution in $\mathrm{Cs}^{137} \beta$-ray spectra by $\mathrm{Cd}_{0.96} \mathrm{Zn}_{0.04}$ Te sample at the field strength $U=2000 \mathrm{~V} / \mathrm{cm}$. The high sensitivity to gammaray radiation of $\mathrm{Ag}^{110 \mathrm{~m}}$ source have been demonstrated for the $\mathrm{Cd}_{0.87} \mathrm{Zn}_{0.13}$ Te-based detector (Fig. 6b). Comparison of its spectra with those obtained by the standard $\mathrm{NaI}(\mathrm{Tl})$ detector measured under identical conditions (Fig. 6c) confirms this conclusion.

\section{Summary}

High-quality structure, high-resistive $\mathrm{Cd}_{1-\mathrm{x}} \mathrm{Zn}_{\mathrm{x}} \mathrm{Te}$ $(x \leq 0.13)$ single crystals of 30 to $35 \mathrm{~mm}$ in diameter were grown from the vapor by contactless method using the polycrystalline ternary compound as the source material. It was obtained that, for preparation of highresistive perfect crystals at high growth rate, there is a need of heat removal from the crystallization front by radiation, not by the crystal thermal conductivity. The obtained crystals were successfully tested for creating the room temperature X-ray and gamma-ray detectors.

\section{References}

1. P. Fougeres, P. Siffert, M. Hageali, J.M. Koebel, and R. Regal // Nucl. Instrum. Meth. Phys. Res. A. 428, p. 38 (1999).

2. M. Schieber, T.E. Schlesinger, R.B. James, H. Hermon, H. Yoon, and M. Goorsky // J. Cryst. Growth 237, p. 2090 (2002).

3. M. Laasch, T. Kunz, C. Eiche, M. Fiederle, W. Joerger, G. Kloess, and K.W. Benz // Ibid. 174, p. 696 (1997).

4. Yu.V. Korostelin, V.I. Kozlovsky // J. Alloys Comp. 371, p. 25 (2004).

5. K. Chattopadhyay, S. Feth, H. Chen, A. Burger, and Ching-Hua Su // J. Cryst. Growth 191, p. 377 (1998).

6. S.G. Parker, J.E. Pinnell, and R.F. Johnson // J. Electron. Mater. 3, p. 731 (1974).

7. N. Tamari, H. Shtrikman // J. Cryst. Growth 43, p. 378 (1978).

8. F.V. Markov, J.P. McVittie // J. Electron. Mater. 3, p. 853 (1974).

9. W. Lo, G.R. Montgomery, and D.E. Swets // J. Appl. Phys. 47, p. 267 (1976).

10. T. Kuntz, M. Laasch, J. Meinhardt, and K.W. Benz // J. Cryst. Growth 184/185, p. 1005 (1998).

11. A.I. Kopyl, D. Letyuchenko // J. Thermoelectricity 3, p. 48 (2002).

12. M. Inoue, I. Teramoto, and S. Takayanaga $/ / J$. Appl. Phys. 33, p. 2578 (1962).

13. G. Indenbaum, N.P. Baronenkova, and I.M. Bojnyh // Fiz. Khim. Obrab. Mater. 2, p. 93 (1971).

14. Yu.M. Ivanov // J. Cryst. Growth 161, p. 12 (1996).

15. J.H. Greenberg // E-MRS Fall Meeting 2002. Symposium G: Solid solutions of the II-VI compounds-growth, characterization and applications. Zakopane, Poland, 2002. Programme and Abstracts. Abstract 22. 